\title{
Are interleukin-16 and thrombopoietin new tools for the in vitro generation of dendritic cells?
}

\author{
Silvia Della Bella, Stefania Nicola, Inna Timofeeva, Maria Luisa Villa, Armando Santoro, and Anna C. Berardi
}

The effects of interleukin 16 (IL-16) on dendritic cell (DC) generation from human $\mathrm{CD}^{+} 4^{+}$progenitor cells are not known. Here, we show that IL-16 added to a basal cocktail comprised of granulocytemacrophage colony-stimulating factor (GM-CSF), IL-4, FIt-3 ligand (FIt3L), and tumor necrosis factor $\alpha$ (TNF- $\alpha)$ does induce the $\mathrm{CD}_{34}{ }^{+}$hematopoietic cells to proliferate in vitro and to differentiate into phenotypically and functionally mature DCs. IL-16 exerts this function more effi- ciently than stem cell factor (SCF) as a control, thrombopoietin (TPO), or IL-16 plus TPO. Moreover, we show that the combination of IL-16 plus TPO induces the generation of tolerogenic DCs, able to induce an anergic state in $\mathrm{T}$ cells that persists when $\mathbf{T}$ cells are rechallenged with immunogenic DCs. An altered pattern of cytokine production, a reduced expression of the C-type lectin DC-SIGN, and an increased surface expression of the inhibitory molecules immunoglobulin- like transcript 2 (ILT-2), ILT-3, and ILT-4 may all contribute to confer the tolerogenic properties of these DCs. Generation of tolerogenic DCs may aid the exploration of new therapeutic strategies to promote tolerance to autoantigens and prevent disease development. (Blood. 2004;104:4020-4028)

(c) 2004 by The American Society of Hematology

\section{Introduction}

Dendritic cells (DCs) are professional antigen-presenting cells (APCs), able to induce primary T-cell activation, polarization, and, in certain circumstances, tolerance. ${ }^{1-3}$ Immature DCs in the periphery capture antigens and then, through inflammatory stimuli, migrate to draining lymph nodes where they present processed antigens to naive T cells. ${ }^{3,4}$ At this more mature stage of their life, DCs up-regulate expression of major histocompatibility (MHC) class II as well as costimulatory molecules, such as CD40, CD80, and CD86. ${ }^{5}$ The ability of DCs to initiate immune responses has focused much attention on the potential use of DCs for immunotherapy. Progress in the understanding of DC biology has been made slowly and with difficulty because of the paucity of these cells in the peripheral blood and in other tissues. In recent years, several investigators successfully generated in vitro human DCs from human peripheral blood monocytes and from human CD34 ${ }^{+}$ cells obtained from various sources such as peripheral blood, cord blood, or bone marrow, by culture with multiple cytokine combinations. Standard monocyte-derived DCs are obtained by culture of monocytes in the presence of granulocyte-macrophage colonystimulating factor (GM-CSF) and interleukin-4 (IL-4) for 5 to 7 days. DCs with immune properties similar to those of mature monocyte-derived DCs can be generated from $\mathrm{CD} 34^{+}$progenitors using combinations of the cytokines stem cell factor (SCF), Flt-3 ligand (Flt3L), GM-CSF, IL-4, and tumor necrosis factor- $\alpha$ (TNF- $\alpha$ ), in cultures lasting 14 days. $^{6}$ In this model system, SCF and Flt3L support the development of hematopoietic progenitors, ${ }^{7,8}$ whereas GM-CSF, IL-4, and TNF- $\alpha$ promote the differentiation into DCs. ${ }^{9-10}$ The use of cytokines other than SCF and Flt3L to expand hematopoietic progenitors could represent a good strategy to improve the system, aimed to obtain larger numbers of cultured DCs that can be used to better define DC biology and for immunotherapeutic purposes.

IL-16 in its biologically active form is a cationic homotetramer of $14-\mathrm{kDa}$ chains, which is unrelated to previously described chemokines or other chemotactic or growth factor cytokines. ${ }^{10,11}$ IL-16 is a chemotactic and activating factor for $\mathrm{CD}^{+} \mathrm{T}$ cells, monocytes, eosinophils, and DCs. The biologic activities of IL-16 depend on the cell surface expression of CD4, ${ }^{12-14}$ through which IL-16 conveys its functional signal. ${ }^{13,14}$ It has been reported that a subpopulation of $\mathrm{CD} 34^{+}$hematopoietic cells expresses CD4 on its surface; it has been suggested that this population may be represented by very early cells. ${ }^{15}$ Therefore, we were interested in exploring whether IL-16 may be a possible candidate cytokine able to induce $\mathrm{CD} 34^{+}$cells to proliferate or differentiate versus DC lineage.

Human stem cells also express the receptor for thrombopoietin (TPO) on their surface. ${ }^{16}$ TPO is a factor endowed with the ability to induce the proliferation of primitive hematopoietic progenitor cells ${ }^{17}$; when combined with Flt3L and SCF, TPO not only induces the generation of long-lasting DC precursors from $\mathrm{CD}_{3} 4^{+}$cells, but also seems to condition the irreversible commitment of CD14 ${ }^{+}$ cells into monocytic lineage. ${ }^{18,19}$

In the present report we provide evidence, for the first time to our knowledge, that IL-16 in combination with Flt3L, GM-CSF, IL-4, and TNF- $\alpha$ can induce $\mathrm{CD}^{+} 4^{+}$hematopoietic cells to proliferate in vitro and to differentiate into phenotypically and functionally mature DCs. IL-16 exerts this function more efficiently than SCF or TPO or IL-16 plus TPO. Moreover, the
From the Dipartimento di Scienze e Tecnologie Biomediche, Laboratorio di Immunologia, Università di Milano, Milan, Italy; Istituto Clinica Humanitas, Laboratorio di Ematologia/Oncologia, Rozzano, Milan, Italy; Ospedale Pediatrico Bambino Gesù, Laboratorio di Ricerche "Cellule Staminali," Rome, Italy.

Submitted March 9, 2004; accepted July 24, 2004. Prepublished online as Blood First Edition Paper, August 10, 2004; DOI 10.1182/blood-2004-03-0885.
Reprints: Anna C. Berardi, Ospedale Pediatrico Bambino Gesù, Laboratorio di ricerche "Cellule Staminali," Piazza S Onofrio, 4, 00165, Roma, Italy; e-mail: annacberardi@yahoo.it.

The publication costs of this article were defrayed in part by page charge payment. Therefore, and solely to indicate this fact, this article is hereby marked "advertisement" in accordance with 18 U.S.C. section 1734

(C) 2004 by The American Society of Hematology 
combination of IL-16 plus TPO induces the generation of tolerogenic DCs, able to induce an anergic state in T cells that persists when $\mathrm{T}$ cells are rechallenged with immunogenic DCs. An altered pattern of cytokine production, a reduced expression of the C-type lectin DC-SIGN, and an increased surface expression of the inhibitory molecules immunoglobulin-like transcript-2 (ILT-2), ILT-3, and ILT-4 may all contribute to confer the tolerogenic properties of these DCs.

\section{Materials and methods}

\section{Isolation of human $\mathrm{CD} 34^{+}$cell progenitors}

Leukapheresis products were obtained from healthy donors and from patients with solid tumors undergoing peripheral blood stem cell (PBSC) mobilization with recombinant human granulocyte-colony stimulating factor (G-CSF) after informed consent was provided. Approval for these studies was obtained from the Instituto Clinical Humanitas institutional review board. Leukapheresis samples contained $0.5 \%$ to $9.1 \% \mathrm{CD}^{2}{ }^{+}$cells. Peripheral blood mononuclear cells (PBMCs) were obtained by Ficoll density gradient centrifugation (Ficoll-Hypaque, Pharmacia Biotech, Uppsala, Sweden). CD34 ${ }^{+}$cells were purified using immunomagnetic selection with mini-magnetic-activated cell sorter (MACS) cell isolation kit (Miltenyi Biotec, Bergisch Gladbach, Germany) according to the manufacturer's instructions.

\section{Generation of DCs from CD34+ progenitor cell cultures}

$\mathrm{CD} 34^{+}$-enriched cells (mean purity $90.0 \% \pm 8.4 \%$ ) were cultured in $25-\mathrm{cm}^{2}$ flasks at $1 \times 10^{5} / \mathrm{mL}$ for 14 days in RPMI 1640 (Gibco Laboratories, Milan, Italy), supplemented with $10 \%$ heat-inactivated fetal calf serum (FCS; Euroclone, Wetherby, United Kingdom), in the presence of a basal cocktail, comprised of human recombinant GM-CSF (50 ng/mL), IL-4 (10 $\mathrm{ng} / \mathrm{mL})$, Flt3L $(50 \mathrm{ng} / \mathrm{mL}), \mathrm{TNF}-\alpha(2.5 \mathrm{ng} / \mathrm{mL})$, plus either SCF $(10 \mathrm{ng} / \mathrm{mL}$; SCF-DCs), or TPO (10 ng/mL; TPO-DCs), or IL-16 (10 ng/mL; IL-16DCs), or IL-16 plus TPO (IL-16/TPO-DCs). All the cytokines were from PeproTech (London, United Kingdom). Each 3 days, half of the culture medium was replaced by fresh medium and growth factors. At the end of the culture, cells were collected and used for subsequent analysis. The cell morphology was assessed on cytospin preparations after May-GrünwaldGiemsa or acridine orange (AO) staining. The peak of DC production occurred at day 14

\section{Cell sorting}

Cell sorting of the $\mathrm{CD} 34^{+} \mathrm{CD} 4^{+}$and $\mathrm{CD} 34^{+} \mathrm{CD} 4^{-}$cells was performed starting from magnetic bead-isolated $\mathrm{CD}_{3} 4^{+}$cells. Purified $\mathrm{CD} 34^{+}$cells $\left(1 \times 10^{6}\right.$ cells $)$ were isolated simultaneously with fluorescein isothiocyanate (FITC; CD34) and phycoerythrin (PE; CD4) using a modified dual laser fluorescence-activated cell sorter (FACS) Vantage (Becton Dickinson, San Jose, CA). Dead cells were excluded from cytometric analysis by propidium iodide (PI) staining. The mean purity of the sorted cells was always more than $99 \%$ for the indicated surface marker phenotype.

\section{Immunophenotypic analysis}

DCs were incubated with different FITC- or PE-conjugated monoclonal antibodies (mAbs) for 30 minutes at $4^{\circ} \mathrm{C}$ in the dark. The following mAbs were used: anti-CD1a, -CD3,-CD4,-CD14, -CD15, -CD19, -CD34, -CD40, -CD41, -CD80, -CD83, -CD86, -HLA-ABC, -HLA-DR (Becton Dickinson); -CD11c (Caltag, Burlingame, CA); -CD123 (PharMingen, San Diego, CA); -CD209 (DC-SIGN; R\&D Systems, Minneapolis, MN); and -ILT-2, -ILT-3, -ILT-4 (a generous gift of Prof E. Berti, University of Milano-Bicocca, Italy). Negative controls were isotype-matched irrelevant mAbs. Cells were collected and analyzed using a FACScan (Becton Dickinson) flow cytometer. Data analysis was performed by CellQuest software (Becton Dickinson). Cells were electronically gated according to light scatter properties to exclude cell debris.

\section{Mannose receptor-mediated endocytosis}

FITC-dextran (Molecular Probes, Eugene, OR) was used to assess cell endocytosis, as described elsewere. ${ }^{20}$ Briefly, $1 \times 10^{5}$ cells were incubated with $1 \mathrm{mg} / \mathrm{mL}$ FITC-dextran at $37^{\circ} \mathrm{C}$ or $0^{\circ} \mathrm{C}$ for 60 minutes. Samples were extensively washed prior to flow cytometry analysis. The level of antigen uptake by DCs was expressed as the difference in mean fluorescence intensity $(\Delta \mathrm{MFI})$ between the test $\left(37^{\circ} \mathrm{C}\right)$ and control $\left(0^{\circ} \mathrm{C}\right)$ tubes for each sample.

\section{Phagocytosis of apoptotic cells}

The ability of DCs to internalize apoptotic cells was assessed as described elsewere. ${ }^{20}$ Briefly, monocyte-depleted PBMCs were labeled with $0.5 \mu \mathrm{M}$ chloro-methyl-fluorescein-diacetate (CMFDA; Molecular Probes) for 30 minutes at $37^{\circ} \mathrm{C}$. Cell apoptosis was induced by 24 -hour treatment with 10 $\mu \mathrm{M} \mathrm{H}_{2} \mathrm{O}_{2}$ and assessed by morphology and staining with PI and AO. The labeled apoptotic cells were subsequently cocultured with CD1a-labeled allogeneic DCs at a 1:1 ratio. After 2 hours, the cells were washed and treated with $0.05 \%$ trypsin $/ 0.02 \%$ EDTA (ethylenediaminetetraacetic acid) for 5 minutes to disrupt cell-to-cell binding. Phagocytosis was quantified by flow cytometry as percentage of double-positive cells $\left(\mathrm{CMFDA}^{+} / \mathrm{CD} \mathrm{a}^{+}\right)$. Negative controls were performed at $0^{\circ} \mathrm{C}$.

\section{Allogeneic and autologous T-cell proliferation assay}

To test their allostimulatory activity, DCs $\left(15 \times 10^{3}\right)$ were cocultured in 96-well plates with $3 \times 10^{5}$ allogeneic, monocyte-depleted PBMCs in triplicate for 5 days. ${ }^{20}$ To test their ability to present soluble antigens to autologous lymphocytes, DCs were incubated with or without influenza virus vaccine (FLU) for 24 hours and then cocultured with autologous, monocyte-depleted PBMCs for 7 days. In all cases, 5-bromo-2' deoxyuridine (BrdU, $20 \mu \mathrm{M}$; Sigma Chemicals, St. Louis, MO) was added in each well during the last 6 hours of culture, and lymphocyte proliferation was assessed by flow cytometry as BrdU incorporation by $\mathrm{CD}^{+}$lymphocytes, as described by Toba et al. ${ }^{21}$ Results were expressed as percentage of proliferating $\left(\mathrm{BrdU}^{+}\right)$lymphocytes.

\section{Tolerance assay}

CD45RA ${ }^{+} \mathrm{CD}^{+}{ }^{+}$naive $\mathrm{T}$ lymphocytes, purified as previously described, ${ }^{20}$ were cocultured with allogeneic SCF-DCs or IL-16/TPO-DCs as for primary allogeneic cultures. After 5 days, the $\mathrm{T}$ cells were harvested, washed, and rested for an additional 2 days in culture medium, as described by Nouri-Shirazi and Guinet. ${ }^{22}$ The rested $\mathrm{T}$ cells from primary cultures were rechallenged in a second proliferation assay with $1.5 \times 10^{4} \mathrm{SCF}-\mathrm{DCs}$, and proliferation assessed as percentage of $\mathrm{BrdU}$-incorporating lymphocytes.

\section{Cytokine measurements}

The release of cytokines in the supernatants of unstimulated DCs was determined by a specific enzyme-linked immunosorbent assay (ELISA). To this aim, $\mathrm{CD} 34^{+}$cells were plated at $2.5 \times 10^{5} / \mathrm{mL}$ in 24 -well plates and cultured as described (see "Generation of DCs from $\mathrm{CD} 34^{+}$progenitor cell cultures"). Supernatants were harvested at the indicated time points, and the concentration of IL-10, IL-12p70, and interferon- $\gamma$ (IFN- $\gamma$ ) was measured by use of commercially available pairs of mAbs (Endogen, Woburn, MA). Transforming growth factor- $\beta$ (TGF- $\beta$ ) and IFN- $\alpha$ were measured with TGF- $\beta 1$ Quantikine (R\&D Systems) and IFN- $\alpha$ ModuleSet (Bender MedSystems, Vienna, Austria), respectively, used according to the manufacturers' instructions.

The production of cytokines by T cells cocultured with allogeneic DCs was determined by flow cytometry as intracellular cytokine expression, as previously described. ${ }^{20}$ Briefly, after the indicated days of DC-T coculture, $\mathrm{T}$ cells were reactivated with 12-myristate-13-acetate (PMA; $25 \mathrm{ng} / \mathrm{mL}$ ) plus ionomycin $(1 \mu \mathrm{g} / \mathrm{mL})$ for 5 hours. Brefeldin-A (BFA; $10 \mu \mathrm{g} / \mathrm{mL}$; Sigma) was added during the last 4 hours to accumulate most of the cytokine in the Golgi complex. Cells were labeled with CD4 mAb, fixed, and permeabilized using Fix\&Perm (Caltag), and then labeled with $\mathrm{mAb}$ against cytokine IL-2, IFN- $\gamma$, or IL-10. 
A

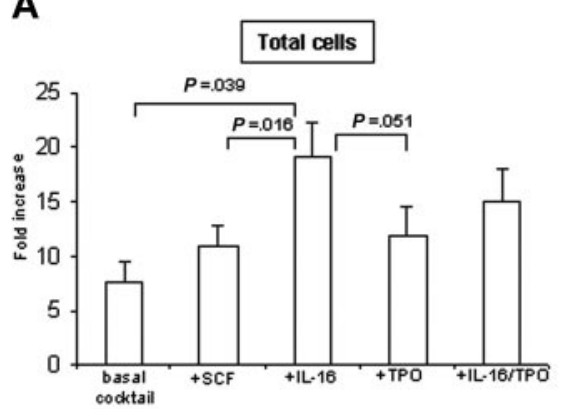

C

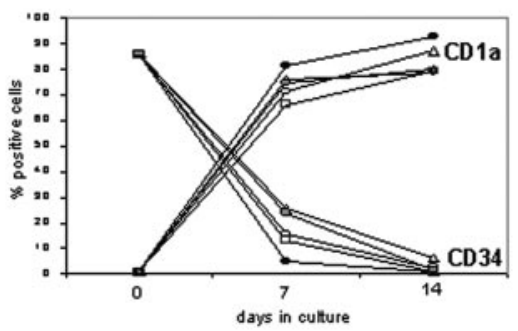

B

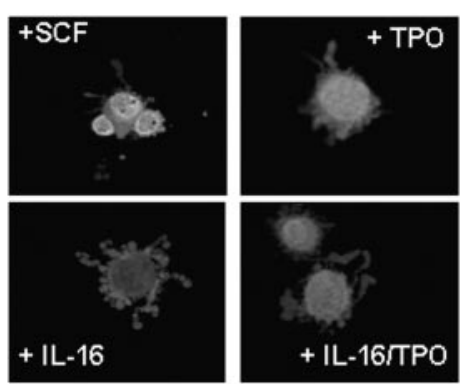

D

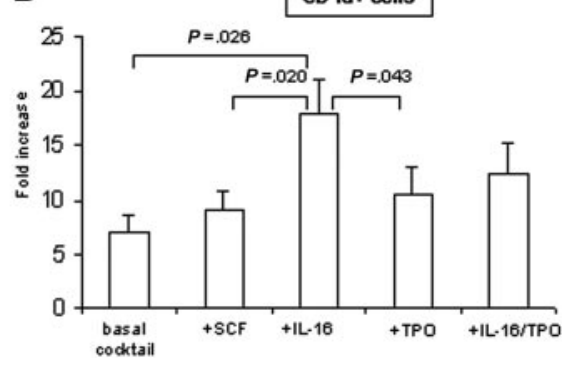

Figure 1. Cell proliferation and differentiation of $\mathrm{CD}^{+}{ }^{+}$progenitor cells in different culture conditions. (A) After 14 days, the total number of cells expanded in vitro in the presence of IL-16 added to the basal cocktail was higher than in the presence of the other cytokine combinations. The mean fold increase over cell number plated on day 0 is shown. Mean \pm SEM from 16 independent experiments. Comparison between treatments performed with the 2-tailed $t$ test. (B) Morphology of the cells after 14 days of culture. The majority of the cells showed lobulated nuclei and numerous fine cytoplasmic projections, as assessed by AO staining Photographs were taken under a Leitz-DIALUX22 fluorescence microscope (Leica, Milan, Italy) equipped with a Kodak DX7590 camera (Kodak-italia, Milan, Italy). Original magnification $\times 400$. No differences were observed among the different culture conditions. (C) Down-regulation of CD34 and up-regulation of CD1a expression after 7 and 14 days of culture in the presence of the different cytokine combinations. L-16 $(\diamond)$ added to the basal cocktail $(\triangle)$ appeared to be more efficient than SCF $(\mathbf{\Delta})$, TPO $(\bullet)$, and IL-16 plus TPO $(\square)$ in inducing the differentiation of $\mathrm{CD}^{+} 4^{+}$cells into DCs. The mean of 9 independent experiments is shown. (D) After 14 days, the number of DCs expanded in vitro in the presence of IL-16 added to the basal cocktail was higher than in the presence of the other cytokine combinations. The mean fold increase, obtained by multiplying the percentage of $\mathrm{CD} 1 \mathrm{a}^{+}$ cells for the absolute number of viable cells, is shown. Mean \pm SEM from 16 independent experiments. Comparison between treatments performed with the 2-tailed $t$ test.

\section{Statistical analysis}

Statistical analysis was performed with Openstat 3 software (open source statistics package by Bill Miller, Iowa State University).

\section{Results}

\section{Cell proliferation and differentiation in cultures of CD34 ${ }^{+}$ progenitor cells}

$\mathrm{CD}_{34}{ }^{+}$fractions ranging in purity from $80 \%$ to $92 \%$ were cultured for 2 weeks in the presence of Flt3L, GM-CSF, IL-4, TNF- $\alpha$ (basal cocktail) plus either SCF as a control, IL-16, TPO, or IL-16 plus TPO. In the presence of IL-16 the total number of in vitro expanded cells was higher (fold increase, mean \pm SEM, $19.04 \pm 3.24$ ) than in the presence of the other growth factors, namely, SCF
$(10.84 \pm 2.01 ; P=.016), \mathrm{TPO}(11.86 \pm 2.79 ; P=.051)$, or IL-16 plus TPO (14.89 \pm 3.03 ; $P$ not significant; Figure $1 \mathrm{~A})$. No differences were observed between cultures of samples collected from healthy donors or patients. Exposure of CD34+ ${ }^{+}$cells to the 4 cytokine combinations led to progressive appearance of typical DC morphology. After 14 days of culture, the majority of the cells showed lobulated nuclei and numerous fine cytoplasmic projections, as assessed by May-Grünwald-Giemsa staining, and confirmed by fluorescence microscopy after AO staining (Figure 1B). IL-16 appeared to be more efficient than the other factors in inducing the differentiation of $\mathrm{CD} 34^{+}$cells into DCs because the cells grown in the presence of IL-16 showed a more rapid and efficient down-regulation of CD34 and surface expression of the DC marker CD1a (Figure 1C; Table 1). After 7 days of culture, the percentage of cells still expressing CD34 was significantly lower in

Table 1. Immunophenotypic pattern of CD34-derived DCs obtained under different culture conditions

\begin{tabular}{|c|c|c|c|c|c|c|c|c|c|c|}
\hline Marker & $\mathrm{BC}, \%$ & $\begin{array}{c}\mathrm{BC}+\mathrm{SCF},{ }^{*} \\
\%\end{array}$ & $\begin{array}{l}B C+I L- \\
16, \dagger \%\end{array}$ & $\begin{array}{c}\mathrm{BC}+\mathrm{TPO}, \boldsymbol{\dagger} \\
\%\end{array}$ & $\begin{array}{c}\text { BC+IL- } \\
16+\text { TPO, } † \\
\%\end{array}$ & BC, MFI & $\mathrm{BC}+\mathrm{SCF},{ }^{\star} \mathrm{MFI}$ & $\begin{array}{c}\text { BC+IL-16, } \\
\text { MFI }\end{array}$ & $\mathrm{BC}+\mathrm{TPO}, \uparrow \mathrm{MFI}$ & $\begin{array}{c}\text { BC+IL-16+TPO, } † \\
\text { MFI }\end{array}$ \\
\hline CD34 & $6.3 \pm 1.2$ & $1.0 \pm 0.6 \ddagger$ & $0.8 \pm 0.3$ & $2.5 \pm 0.6 \ddagger$ & $1.4 \pm 0.8$ & $17.6 \pm 2.9$ & $6.8 \pm 1.8 \ddagger$ & $4.5 \pm 1.2 \S$ & $9.4 \pm 2.3 \S$ & $8.3 \pm 2.1$ \\
\hline CD14 & $0.2 \pm 0.1$ & $0.5 \pm 0.4$ & $0.3 \pm 0.2$ & $0.3 \pm 0.1$ & $0.4 \pm 0.1$ & $2.9 \pm 0.4$ & $3.4 \pm 0.6$ & $2.8 \pm 0.3$ & $2.7 \pm 0.5$ & $3.7 \pm 0.4$ \\
\hline CD1a & $78.5 \pm 11.2$ & $79.1 \pm 7.4$ & $93.0 \pm 3.1 \ddagger$ & $87.1 \pm 5.7 \ddagger$ & $80.0 \pm 6.5$ & $134.6 \pm 11.3$ & $287.1 \pm 124.5$ & $342.8 \pm 182.1$ & $294.2 \pm 86.9$ & $210.7 \pm 78.8$ \\
\hline CD80 & $79.3 \pm 8.1$ & $82.9 \pm 3.5$ & $96.3 \pm 2.2 \ddagger$ & $87.7 \pm 5.8 \S$ & $89.7 \pm 5.4 \ddagger$ & $814.3 \pm 51.6$ & $844.5 \pm 115.3$ & $1004.0 \pm 70.0 \S$ & $970.1 \pm 110.2 \S$ & $982.3 \pm 75.7 \S$ \\
\hline CD86 & $52.9 \pm 2.3$ & $58.0 \pm 8.7$ & $66.6 \pm 7.5 \S$ & $68.0 \pm 7.7 \ddagger$ & $66.3 \pm 7.3 \S$ & $273.6 \pm 43.3$ & $402.1 \pm 103.4 \S$ & $795.4 \pm 38.1 \neq$ & $567.3 \pm 119.1 \neq$ & $570.6 \pm 29.3 \ddagger$ \\
\hline CD40 & $8.2 \pm 0.2$ & $8.4 \pm 1.7$ & $19.5 \pm 1.1 \ddagger$ & $8.6 \pm 1.0$ & $10.7 \pm 1.6 \S$ & $35.6 \pm 3.7$ & $37.0 \pm 3.1$ & $71.2 \pm 3.2 \ddagger$ & $47.3 \pm 4.6 \ddagger$ & $44.5 \pm 9.4 \S$ \\
\hline CD83 & $3.1 \pm 1.0$ & $2.5 \pm 0.7$ & $12.3 \pm 0.6 \neq$ & $6.1 \pm 1.8 \ddagger$ & $6.2 \pm 1.9 \ddagger$ & $21.6 \pm 6.7$ & $23.0 \pm 7.2$ & $57.7 \pm 4.5 \ddagger$ & $39.4 \pm 4.4 \ddagger$ & $47.1 \pm 6.4 \ddagger$ \\
\hline HLA-ABC & $97.2 \pm 0.4$ & $96.8 \pm 1.9$ & $96.1 \pm 3.4$ & $98.2 \pm 0.6$ & $98.5 \pm 0.8$ & $1702.0 \pm 87.4$ & $2146.3 \pm 183.7 \S$ & $2293.7 \pm 165.2$ & $2195.0 \pm 163.8$ & $2246.3 \pm 131.8$ \\
\hline HLA-DR & $97.0 \pm 1.5$ & $93.8 \pm 3.9$ & $94.6 \pm 4.6$ & $90.2 \pm 3.3$ & $95.9 \pm 2.5$ & $1660.0 \pm 148.9$ & $1843.5 \pm 86.0 \S$ & $1927.5 \pm 93.8$ & $1906.6 \pm 173.1$ & $2172.6 \pm 200.3 \ddagger$ \\
\hline CD4 & $91.7 \pm 7.1$ & $88.5 \pm 5.8$ & $92.4 \pm 3.3$ & $89.3 \pm 3.5$ & $87.9 \pm 2.7$ & $538.3 \pm 72.9$ & $566.8 \pm 94.4$ & $802.4 \pm 58.7 \ddagger$ & $819.6 \pm 59.5 \ddagger$ & $815.8 \pm 44.8 \ddagger$ \\
\hline CD11c & $96.5 \pm 3.3$ & $94.9 \pm 3.2$ & $96.6 \pm 3.5$ & $94.2 \pm 3.4$ & $99.4 \pm 0.2$ & $605.7 \pm 13.6$ & $609.3 \pm 19.1$ & $606.9 \pm 16.6$ & $606.9 \pm 20.9$ & $611.7 \pm 8.2$ \\
\hline CD123 & $43.4 \pm 5.6$ & $38.7 \pm 13.9$ & $48.3 \pm 19.9$ & $65.4 \pm 12.1 \S$ & $68.1 \pm 2.9 \S$ & $70.8 \pm 9.3$ & $58.4 \pm 19.2$ & $61.8 \pm 24.0$ & $95.6 \pm 26.1 \S$ & $111.5 \pm 11.1 \S$ \\
\hline
\end{tabular}

DCs generated in vitro by culture of CD $34^{+}$cells with GM-CSF + IL-4+FIt3L + TNF- $\alpha$ (basal cocktail) plus either SCF or IL-16 or TPO or IL-16+TPO were analyzed after 14 days as described in "Materials and methods." Results report the mean \pm SD of 16 independent experiments. CD11c and CD123 were performed on 5 experiments.

$\mathrm{BC}$ indicates basal cocktail.

${ }^{*}$ Compared with BC.

†Compared with SCF

$\ddagger P \leq .005$ ( $t$ test for independent samples).

$\S P<.05$. 
the presence of IL-16 (mean \pm SEM, $5.2 \% \pm 0.4 \%$ ) than in the presence of the basal cocktail alone $(25.4 \% \pm 1.8 \% ; P<.001)$ or with SCF $(13.3 \% \pm 2.0 \% ; P=.004)$, TPO $(15.6 \% \pm 0.9 \%$; $P<.001)$, or IL-16 plus TPO $(24.0 \% \pm 0.8 \%$; $P<.001)$. Moreover, after 7 days of culture the percentage of cells already expressing CD1a was significantly higher in the presence of IL-16 (mean \pm SEM, $81.4 \% \pm 1.2 \%$ ) than in the presence of the basal cocktail alone $(76.1 \% \pm 6.4 \%)$, or with $\mathrm{SCF}(66.3 \% \pm 2.7 \%$; $P<.001)$, TPO $(71.4 \% \pm 1.6 \% ; P=.001)$, or IL-16 plus TPO $(74.4 \% \pm 1.6 \% ; P=.005)$. After 14 days of culture, the superior efficiency of IL-16 in the differentiation process of DCs was still more evident when the yield of DCs generated in vitro, obtained by multiplying the percentage of $\mathrm{CD} \mathrm{a}^{+}$cells for the absolute number of viable cells, expressed as fold increase, was considered (Figure 1D).

Next, we investigated whether the effects of IL-16 were mainly exerted on the $\mathrm{CD}_{3} 4^{+}$subpopulation that expresses CD4. ${ }^{15}$ To this purpose, we cultured $\mathrm{CD} 34^{+} \mathrm{CD} 4^{+}$and $\mathrm{CD} 34^{+} \mathrm{CD} 4{ }^{-}$sorted cells with the basal cocktail in the presence or absence of IL-16. As shown in Figure 2A, IL-16 induced a cell expansion of the $\mathrm{CD} 34^{+} \mathrm{CD} 4^{+}$cells significantly higher than the basal cocktail alone (fold increase, mean \pm SEM, $46.77 \pm 5.80$ versus $33.28 \pm 5.22$; paired Wilcoxon signed rank test; $P=.006)$. The effects of IL-16 on cell expansion of CD $34^{+} \mathrm{CD} 4{ }^{-}$ cells were only marginal $(30.03 \pm 4.40$ versus $25.96 \pm 4.02 ; P$ not significant). Similar results were observed when the yield of DCs was considered (Figure 2B).

\section{Immunophenotype of cultured cells}

The immunophenotype of the cells cultured in the presence of the different cytokine combinations was analyzed after 7 and 14 days of culture. As shown in Table 1, the percentage of cells still expressing CD34 or CD14 at the end of the culture was negligible in all the culture conditions, except for culture with the basal cocktail alone. The contamination of lymphocytes $\left(\mathrm{CD} 3^{+}\right.$or $\left.\mathrm{CD} 19^{+}\right)$and megakaryocytes $\left(\mathrm{CD} 41^{+}\right)$was also negligible $(<1 \%)$ in all the conditions tested and granulocytes $\left(\mathrm{CD} 15^{+}\right)$did not exceed $10 \%$, without differences among treatments.

Compared with SCF-DCs, IL-16-DCs, TPO-DCs, and IL-16/ TPO-DCs appeared more activated because they showed increased expression of the costimulatory molecules CD80, CD86, and CD40 (Table 1). IL-16-DCs had the most activated profile, with expression of CD80 as well CD40 significantly higher than TPO-DCs $(P<.003$ and $P<.001$, respectively) and IL-16/TPO-DCs $(P<.001$ in both cases $)$. As shown in Table 1 , IL-16-DCs,
TPO-DCs, and IL-16/TPO-DCs appeared also more mature than SCF-DCs, as assessed by expression of the maturation marker CD83. Again, IL-16-DCs were the most mature, with CD83 expression significantly higher than TPO-DCs $(P<.001)$ and IL-16/TPO-DCs $(P<.001)$. In 5 cases we analyzed the expression of the plasmacytoid marker CD123 and myeloid marker CD11c. TPO-DCs and IL-16/TPO-DCs had higher expression of CD123 than DCs grown in the absence of TPO (compared with SCF-DCs: $P=.018$ and $P=.012$, respectively). CD123 was coexpressed with CD11c, which was present on the majority of DCs in all the culture conditions (Table 1).

The immunophenotypic characterization of the cells obtained by culture of $\mathrm{CD} 34{ }^{+} \mathrm{CD} 4{ }^{+}$and $\mathrm{CD} 34^{+} \mathrm{CD} 4{ }^{-}$sorted cells documented a progressive expression of CD4 molecule on the surface of the $\mathrm{CD} 34^{+} \mathrm{CD}^{-}$subpopulation $\left(\mathrm{CD}^{+}{ }^{+}\right.$cells, $75.9 \% \pm 9.18 \%$ at day $7 ; 85.4 \% \pm 4 \%$ at day 14 ), both in the absence and presence of IL-16. A representative time-course experiment is shown in Figure $2 \mathrm{C}$. As in the case of unfractioned cells, also in the sorted cell preparations IL-16 induced a higher expression of the activation and maturation markers than the basal cocktail alone, with similar patterns observed in the $\mathrm{CD} 34^{+} \mathrm{CD} 4^{+}$and $\mathrm{CD} 34^{+} \mathrm{CD} 4^{-}$cultures (data not shown).

\section{Antigen capture capacity of DCs}

The capacity of DCs to take up antigens was measured in 2 systems using FITC-dextran, as an indicator of mannose-receptor (MR)mediated endocytosis, and CMFDA-labeled apoptotic cells, as an indicator of phagocytosis. DCs obtained by culture with IL-16 or TPO were as efficient as SCF-DCs, as a control, in capturing antigens. In fact, similar levels of FITC-dextran uptake were presented by SCF-DCs $(\triangle \mathrm{MFI}, 41.2 \pm 1.7$, mean \pm SEM of 5 independent experiments), IL-16-DCs $(39.3 \pm 1.7)$, TPO-DCs $(35.9 \pm 2.1)$, and IL-16/TPO-DCs $(37.0 \pm 3.0)$. Similarly, phagocytosis of CMFDA-labeled apoptotic cells $(>70 \%$ dead cells as determined by PI and AO staining), assessed by flow cytometry as the percentage of CD1a-labeled DCs that expressed the green dye CMFDA and confirmed by the increased granularity of the double-positive population at forward scatter/side scatter analysis, did not differ among DCs obtained with different cytokine combinations (data not shown).

\section{Lymphocyte proliferation induced by DCs}

Next, we evaluated the allostimulatory proprieties of the DCs obtained by culture in the different cytokine combinations. To this
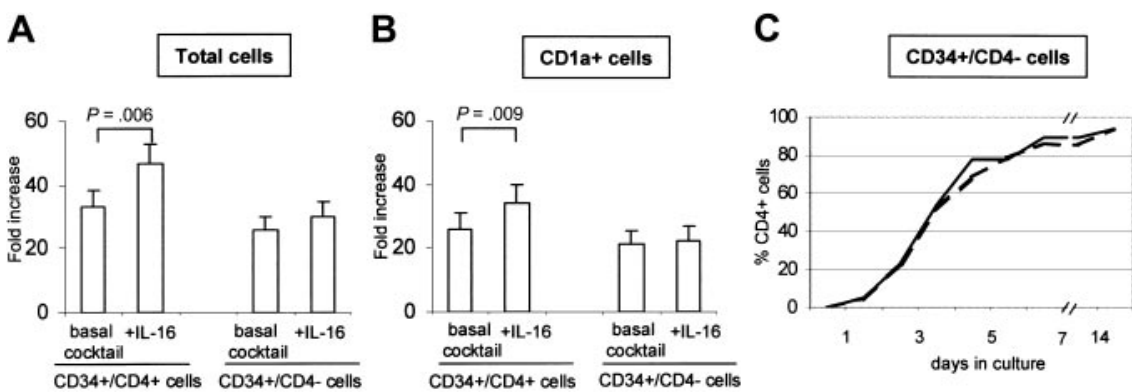

Figure 2. Cell proliferation and differentiation of $\mathrm{CD} 34^{+} / \mathrm{CD} 4^{+}$and $\mathrm{CD} 34^{+} / \mathrm{CD}^{-}$sorted cells culture with or without IL-16. (A) After 14 days, the total number of cells expanded in vitro from $\mathrm{CD} 34^{+} / \mathrm{CD} 4^{+}$cells, but not from CD34 ${ }^{+} / \mathrm{CD} 4^{-}$cells, in the presence of IL- 16 added to the basal cocktail was higher than in the presence of the cocktail alone. The mean fold increase over cell number plated on day 0 is shown. Mean \pm SEM from 10 independent experiments. (B) After 14 days, the number of DCs expanded in vitro from $\mathrm{CD} 34^{+} / \mathrm{CD} 4^{+}$cells, but not from CD34 ${ }^{+} / \mathrm{CD} 4^{-}$cells, in the presence of IL-16 added to the basal cocktail was higher than in the presence of the cocktail alone. The mean fold increase is shown. Mean \pm SEM from 10 independent experiments. Comparison between treatments performed with the paired Wilcoxon signed rank test. (C) $\mathrm{CD}_{3}{ }^{+} / \mathrm{CD} 4^{-}$sorted cells grown in the presence of basal cocktail alone (broken line) or with IL-16 (solid line) showed a progressive expression of CD4 molecule on their surface. One representative of 2 independent experiments is shown. 
A
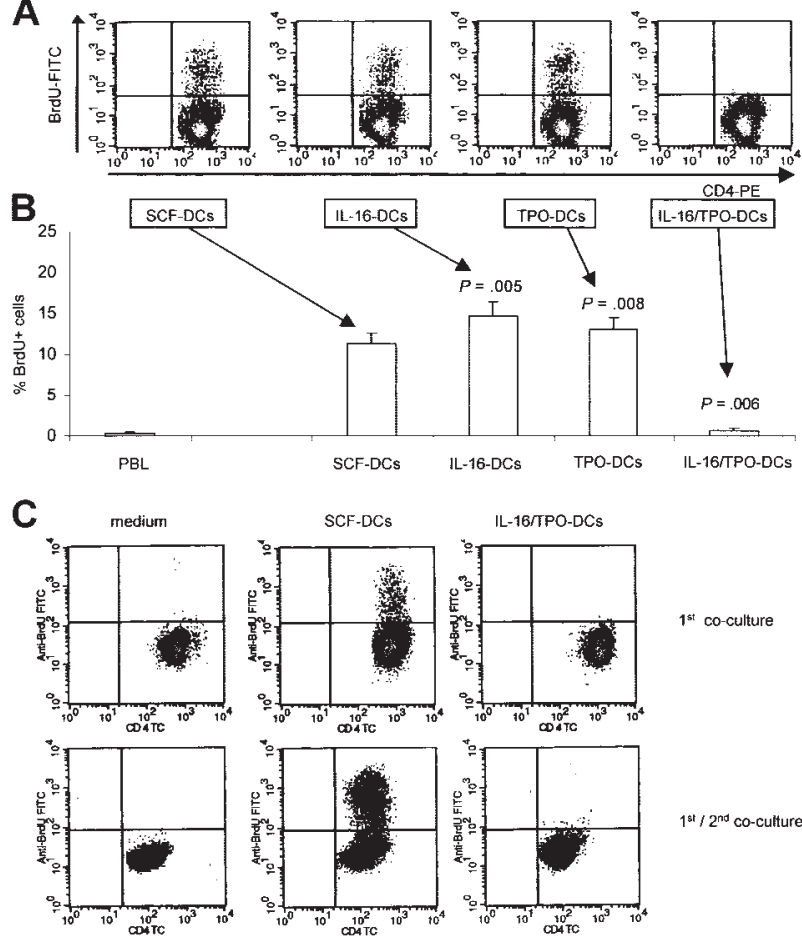

$1^{\text {st }}$ co-culture
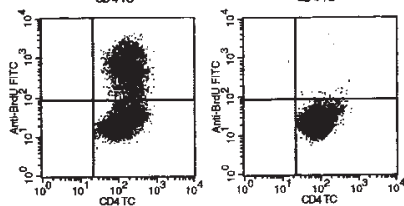

$1^{\text {st } / 2 \text { 2nd }}$ co-culture

Figure 3. Induction of lymphocyte proliferation in primary and secondary allogeneic cultures. (A) The allostimulatory activity of DCs obtained in the different cytokine combinations was tested in primary cultures, using monocyte-depleted PBMCs. Proliferating lymphocytes were identified in density plots as $\mathrm{CD}^{+} / \mathrm{BrdU}^{+}$ double-positive cells. (B) In primary cultures, IL-16-DCs and TPO-DCs showed higher allostimulatory activity than control SCF-DCs, whereas IL-16/TPO-DCs were unable to stimulate the proliferation of allogeneic T lymphocytes. The mean \pm SEM from 9 independent experiments is shown. IL-16-DCs, TPO-DCs, and IL-16/TPODCs compared with SCF-DCs with the paired Wilcoxon signed rank test. (C) Tested in a 2-step culture system, IL-16/TPO-DCs induced tolerance of cocultured T cells. Purified naive T cells were cultured alone (left column) or cocultured with either SCF-DCs (center column) or IL-16/TPO-DCs (right column). After 5 days, the T cells were harvested, washed, and rested for 2 days. The rested T cells from primary cultures were subsequently rechallenged with SCF-DCs. Proliferation of T lymphocytes was assessed as BrdU incorporation after 4 days. One representative of 3 independent experiments is shown.

purpose, the direct pathway of alloantigen presentation was assessed in mixed leukocyte reaction as BrdU incorporation by allogeneic, monocyte-depleted PBMCs. As shown in Figure 3A-B, IL-16-DCs and TPO-DCs showed excellent allostimulatory activity, even superior to that of the control SCF-DCs (percent $\mathrm{BrdU}^{+}$ lymphocytes, mean \pm SEM of 9 independent experiments: SCFDCs, $11.22 \pm 1.40$; IL-16-DCs, $14.61 \pm 1.87$, paired Wilcoxon signed rank test compared with SCF-DCs, $P=.005$; TPO-DCs, $13.00 \pm 1.55, P=.008$ ). Surprisingly, IL-16/TPO-DCs were unable to stimulate the proliferation of allogeneic T-cells $(0.68 \pm$ $0.22, P=.006$ ). In a few experiments, we analyzed the surface expression of the activation marker CD 25 by T cells that had been cocultured in primary allogeneic culture either with IL-16/TPODCs or with standard immunogenic SCF-DCs. We found that the reduced T-cell proliferative response induced by IL-16/TPO-DCs was paralleled by a reduced activation of T cells (percent $\mathrm{CD} 25^{+}$ lymphocytes, mean \pm SEM of 3 independent experiments: SCFDCs, $25.99 \pm 2.84$; IL-16/TPO-DCs, $2.18 \pm 0.49$ ). To further determine whether IL-16/TPO-DCs induced tolerance of naive alloreactive $\mathrm{T}$ cells, we tested the proliferative response of $\mathrm{T}$ cells in a 2-step culture system. As shown in Figure 3C, $\mathrm{T}$ cells cocultured with SCF-DCs in the first coculture responded robustly to rechallenge with the same stimulators. In contrast, the $\mathrm{T}$ cells cocultured with IL-16/TPO-DCs in the first culture were hyporesponsive to further stimulation with SCF-DCs. To better define the role of IL-16 and TPO in conditioning the tolerogenic properties of IL-16/TPO-DCs, we performed kinetic experiments in which IL-16 and TPO were added to or removed from the cultures at different times during the differentiation process of DCs. As shown in Figure $4 \mathrm{~A}$, the removal of IL-16 plus TPO early or late during the first week of culture of IL-16/TPO-DCs was enough to generate DCs endowed with excellent allostimulatory capacity. Figure 4B shows that the single removal of either IL-16 or TPO early or late during the first week of culture was enough to restore the allostimulatory capacity of IL-16/TPO-DCs. Therefore, the concomitant presence of IL-16 and TPO during the first 7 days of coculture was required to induce the differentiation of IL-16/TPO-DCs lacking Tstimulatory activity. We next investigated the effects of IL-16/TPO combination on sorted $\mathrm{CD} 34^{+} / \mathrm{CD} 4^{+}$and $\mathrm{CD} 34^{+} / \mathrm{CD} 4^{-}$cell subpopulations. As shown in Figure 4C, we observed that IL-16 plus TPO induced from both cell subsets the generation of DCs unable to stimulate the proliferation of allogeneic $\mathrm{T}$ cells.

Last, we analyzed the ability of DCs to present influenza virus vaccine (FLU), as a soluble antigen, to autologous lymphocytes. We measured BrdU incorporation by autologous $\mathrm{CD} 4^{+}$lymphocytes cultured with FLU-pulsed DCs. As shown in Figure 5, the excellent APC capacity of IL-16-DCs and TPO-DCs observed in mixed lymphocyte reaction (MLR) was confirmed in this experimental model. On the other hand, IL-16/TPO-DCs were unable to induce lymphocyte proliferation on presentation of FLU, thus confirming the tolerogenic profile of these DCs.

\section{Cytokine production by DCs and T cells}

DC-derived cytokines were measured by ELISA in the supernatants of unstimulated DC cultures. Figure 6A shows kinetic
A

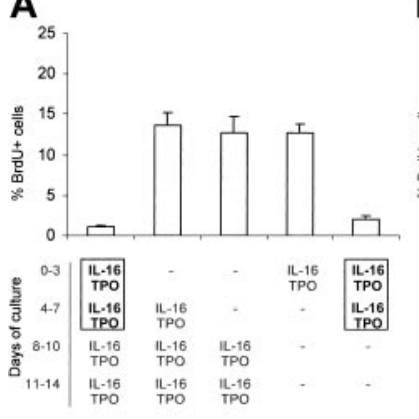

B

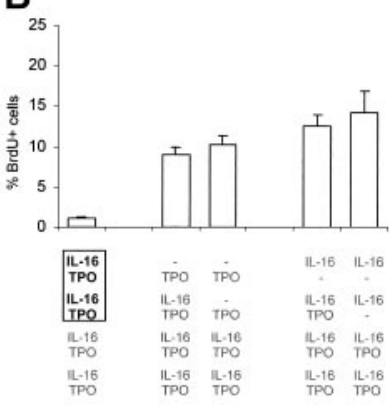

\section{C}
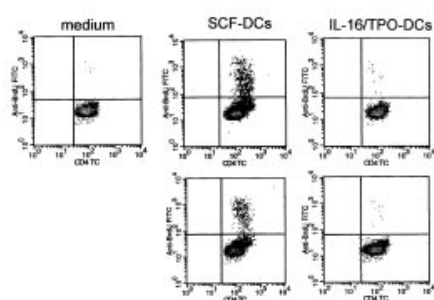

$\mathrm{CD} 34+/ \mathrm{CD} 4+$ cells

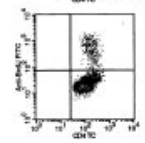

Figure 4. Effects of IL-16/TPO combination on the generation of tolerogenic DCs. The allostimulatory activity of DCs was tested in primary cultures, using monocyte-depleted PBMCs. (A-B) Effects of the presence of IL-16 and TPO at different times of culture. The concomitant presence of IL-16 and TPO during the first 7 days of culture was required to induce the differentiation of tolerogenic DCs. The mean \pm SEM from 3 independent experiments is shown. (C) Effects of IL-16/TPO combination on sorted cell subpopulations. The presence of IL-16 plus TPO induced the generation of tolerogenic DCs, which were unable to stimulate the proliferation of allogeneic $T$ lymphocytes, from both $\mathrm{CD} 34^{+} / \mathrm{CD} 4^{+}$(top row) and $\mathrm{CD} 34^{+} / \mathrm{CD} 4$ (bottom row) cells. Proliferating lymphocytes identified as $\mathrm{CD}^{+} / \mathrm{BrdU}^{+}$doublepositive cells. One representative of 4 independent experiments is shown. 


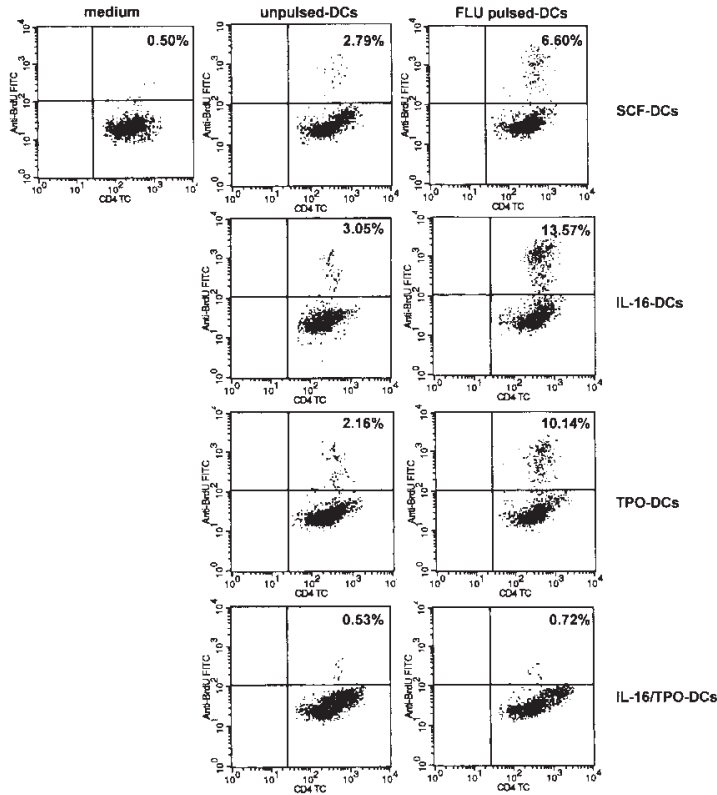

Figure 5. Induction of proliferation of autologous lymphocytes on presentation of a soluble antigen, FLU. The lack of T-stimulatory activity of IL-16/TPO-DCs was confirmed when the proliferation of autologous T lymphocytes on presentation of FLU was tested. The capacity of DCs obtained in the different cytokine combinations to induce T-cell proliferation was compared. Proliferating lymphocytes were identified in density plots as $\mathrm{CD}^{+} / \mathrm{BrdU}^{+}$double-positive cells. Control cultures included monocyte-depleted PBMCs alone (left column), cocultured with unpulsed DCs (middle column), or antigen-specific proliferation assessed in cultures with FLU-pulsed DCs (right column). The numbers represent the percentage of cells in each quadrant. One representative of 3 independent experiments is shown.

experiments aimed at comparing cytokine production at different time points during the differentiation process of DCs grown in the different cytokine combinations. The analysis of cytokine production at the end of the differentiation process indicated that, as shown in Figure 6B, tolerogenic IL-16/TPO-DCs produced markedly higher levels of the immunosuppressive cytokines TGF- $\beta$ and IL-10, and lower levels of the stimulatory cytokine IL-12p70, than standard immunogenic SCF-DCs. Also IL-16-DCs and TPO-DCs produced higher levels of IL-10 than SCF-DCs, but at lower levels than IL-16/TPO-DCs. Unlike the other types of DCs, IL-16/TPODCs also produced IFN- $\alpha$. As shown in Figure $6 \mathrm{~B}$, the pattern of cytokine production of SCF-DCs and IL-16/TPO-DCs obtained from either $\mathrm{CD} 34^{+} / \mathrm{CD} 4^{+}$or $\mathrm{CD} 34^{+} / \mathrm{CD} 4^{-}$sorted cells was similar to that of DCs obtained from unfractionated cells. The production of IFN- $\gamma$ was negligible by DCs cultured in all the cytokine combinations (not shown).

To better characterize the effects of IL-16/TPO-DCs compared with standard SCF-DCs on T lymphocytes, we analyzed the production of cytokines involved in cell activation and proliferation, by $\mathrm{T}$ lymphocytes cocultured with DCs. Because we performed bidirectional allogeneic cultures, we analyzed by flow cytometry intracellular cytokine expression by T lymphocytes. In accordance with the proliferative responses, we observed that following culture with SCF-DCs T lymphocytes expressed IL-2 and IFN- $\gamma$, whereas following culture with IL-16/TPO-DCs they failed to express both cytokines (Figure 6C). T-cell expression of IL-10 was undetectable on culture with either stimulator.

\section{Expression of DC-SIGN and of the inhibitory molecules ILT-2, ILT-3, and ILT-4 on DC surface}

To investigate other mechanisms possibly contributing to the tolerogenic profile of IL-16/TPO-DCs, we next examined the expression on the DC surface of additional molecules involved in DC/T-cell interactions. Therefore, we analyzed the DC expression of the C-type lectin DC-SIGN and found that although the percentage of DCs expressing DC-SIGN in IL-16-DCs and TPODCs was similar to that observed in the control SCF-DCs (percent DC-SIGN $^{+}$DCs, mean \pm SEM of 4 independent experiments: $57.6 \pm 4.4,52.6 \pm 3.1$, and $45.1 \pm 8.8$, respectively), the percentage of DC-SIGN ${ }^{+}$in IL-16/TPO-DCs was markedly decreased $(20.5 \pm 1.1$, Wilcoxon signed rank test, $P=.010$; Figure 7$)$. DC-SIGN expression was directly correlated with lymphocyte proliferation induced in allogeneic cultures (Spearman rank correlation: Rho $=0.626, P=.016)$. Moreover, we examined DC
A

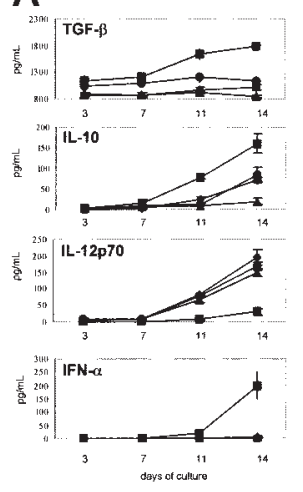

B

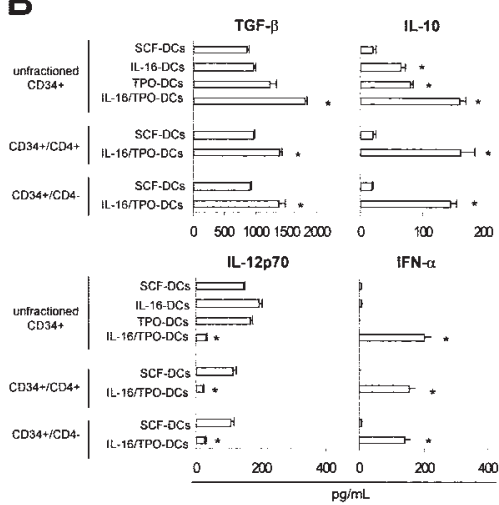

C
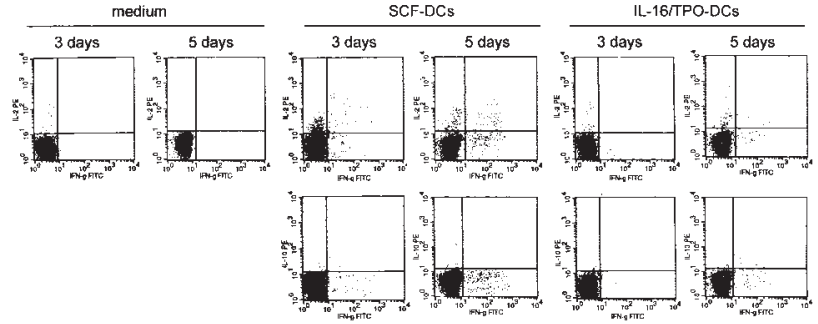

Figure 6. Production of cytokines by DCs and T cells. (A) Production of cytokines at different time points during the differentiation process of DCs grown in different cytokine combinations. CD34+ cells were cultured in the presence of SCF $(\mathbf{\Delta})$, IL-16 $(\bullet)$, TPO $(\bullet)$, or IL-16 plus TPO ( $\square$ ), and the released cytokines were measured in the supernatants by ELISA. The concomitant presence of IL-16 and TPO induced the production of higher levels of TGF- $\beta$, IL-10, and IFN- $\alpha$, and lower levels of IL-12p70, which became increasingly evident during the second week of culture. The mean \pm SEM from 2 independent experiments is shown. (B) Production of cytokines by DCs. Unfractionated $\mathrm{CD}_{3}{ }^{+}$cells, $\mathrm{CD} 34^{+} / \mathrm{CD}^{+}$, and $\mathrm{CD} 34^{+} / \mathrm{CD} 4^{-}$sorted cells were grown in the presence of the indicated cytokine combinations for 14 days, and the released cytokines were measured in the supernatants by ELISA. IL-16/TPO-DCs obtained either from unfractionated CD34 ${ }^{+}$cells or from CD34 ${ }^{+} / \mathrm{CD}^{+}{ }^{+}$or CD34 ${ }^{+} / \mathrm{CD}_{4}^{-}$cells produced higher levels of TGF- $\beta$, IL-10, and IFN- $\alpha$, and lower levels of IL-12p70, than the other types of DCs. Mean \pm SEM from 4 independent experiments. IL-16-DCs, TPO-DCs, and IL-16/TPO-DCs compared with SCF-DCs with the paired Wilcoxon signed rank test; ${ }^{*} P<.05$. (C) Production of cytokines by T cells cocultured with IL-16/TPO-DCs compared with SCF-DCs. Monocyte-depleted PBMCs were cultures alone (left columns), or with SCF-DCs (central columns), or with IL-16/TPO-DCs (right columns). After the indicated days of DC/T coculture, $\mathrm{T}$ cells were reactivated with PMA and ionomycin for 5 hours, and their intracellular expression of cytokines detected by flow cytometry. Gated on CD4+ ${ }^{+}$cells, density plots show the expression of IFN- $\gamma$ and IL-2 (upper row) or IL-10 (lower row). Quadrants were set according to the fluorescence intensities of isotype-matched controls. T cells cocultured with IL-16/TPO-DCs failed to express IL-2 and IFN- $\gamma$. IL-10 was not expressed in any condition. One representative of 3 independent experiments is shown. 
expression of the inhibitory molecules ILT-2, ILT-3, and ILT-4. As shown in Figure 7, the expression of these molecules was markedly increased in IL-16/TPO-DCs compared with control SCF-DCs (percent ILT-2 ${ }^{+}$DCs, $44.3 \pm 10.4$ versus $15.9 \pm 2.8, P=.025$; percent ILT- $3^{+}$DCs, $33.9 \pm 8.1$ versus $6.2 \pm 0.6, P=.025$; percent ILT-4 ${ }^{+}$DCs, $35.3 \pm 7.6$ versus $\left.4.6 \pm 0.2, P=.025\right)$. The expression of ILT-2, ILT-3, and ILT-4 by DCs was inversely correlated with the proliferative response induced in allogeneic cultures (ILT-2, Rho $=-0.798, P=.003$; ILT-3, Rho $=-0.560$, $P=.073 ;$ ILT-4, Rho $=-0.661, P=.027)$.

\section{Discussion}

Our data demonstrate for the first time that IL-16, added to a basal cocktail of cytokines composed of Flt3L, GM-CSF, IL-4, and $\mathrm{TNF}-\alpha$, can induce human $\mathrm{CD}_{3} 4^{+}$cells obtained from $\mathrm{G}-\mathrm{CSF}-$ mobilized blood of adult individuals, to proliferate and differentiate into fully mature DCs. Compared with other growth factors, namely, SCF (used as a control), TPO, or IL-16 plus TPO, IL-16 exerted this function more efficiently, as indicated by the observation that after 14 days of culture the total number of cells expanded in vitro in the presence of IL-16 was higher than in the presence of the other growth factors. IL-16 also induced the differentiation of higher numbers of $\mathrm{CD} \mathrm{a}^{+}$DCs than did the other growth factors. The physiologic in vivo relevance of these results is possibly supported by the notion that $\mathrm{CD} 34^{+}$cells are able to secrete IL-16 themselves, thus suggesting that IL-16 could play a key role, with other endogenously secreted factors, in the biology of early hematopoietic cells. ${ }^{23}$ A better understanding of the role of IL-16 in regulating the biology of human hematopoietic cells will rely on a fine characterization of the structure and the function of this molecule, both of which are currently under intense investigation.

Next, we proceeded to the functional characterization of the DCs obtained with the different cytokine combinations. We found that IL-16-DCs had a more activated and mature immunophenotype than the other DCs, as assessed by a higher expression of the costimulatory molecules CD80, CD86, CD40, and the maturation marker CD83. Notably, this higher stage of maturation did not affect the ability of these cells to internalize antigens. In fact, the DCs obtained with all the cytokine combinations showed similar good capacities to capture antigens either by MR-mediated endocy-

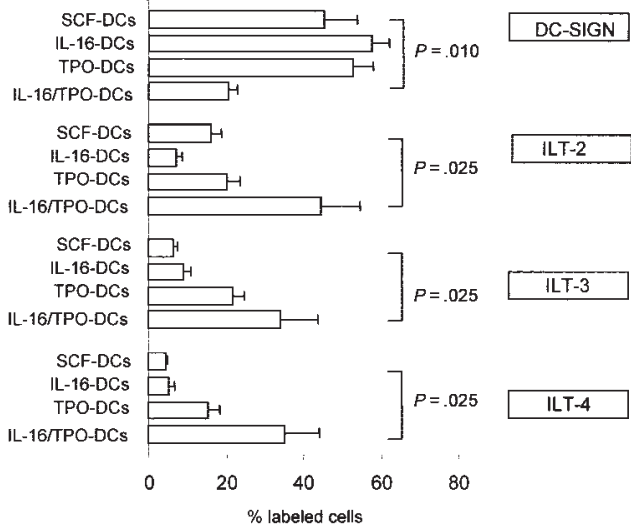

Figure 7. Expression of DC-SIGN and of ILT-2, ILT-3, and ILT-4 by DCs. The frequency of DCs expressing DC-SIGN was markedly lower in IL-16/TPO-DCs compared with the DCs grown in the other cytokine combinations. In the same cells the frequency of DCs expressing ILT-2, ILT-3, and ILT-4 was markedly higher. The mean \pm SEM of 4 independent experiments is shown. Comparison between treatments performed with the paired Wilcoxon signed rank test. tosis or by phagocytosis. Moreover, IL-16-DCs were endowed with excellent APC function, measured as allostimulatory activity and ability to induce T-cell proliferation on presentation of FLU. In this respect, IL-16-DCs were quite similar to SCF-DCs, used as a control, and to TPO-DCs. All together, these results seem to suggest that the substitution of standard SCF with either IL-16 or, to a lesser extent, TPO may represent alternative tools to improve the efficiency of in vitro generation of immunogenic DCs.

IL-16/TPO-DCs were tolerogenic. In fact, in primary cultures they were unable to stimulate the proliferation of either allogeneic $\mathrm{T}$ cells or autologous $\mathrm{T}$ cells on presentation of influenza virus vaccine. This lack of proliferation resulted from the ability of IL-16/TPO-DCs to induce an anergic state in T cells, documented by low expression of CD25, IL-2, and IFN- $\gamma$ in cocultured T lymphocytes, which persisted when IL-16/TPO-DC-conditioned T cells were rechallenged with immunogenic SCF-DCs. The concomitant presence of IL-16 and TPO during the first 7 days of culture was required to induce tolerogenic DCs, as indicated by kinetic experiments. Because treatment of developing DCs with TGF- $\beta$ or IL-10 or both promotes the generation of tolerogenic DCs, ${ }^{24-26}$ we asked whether induction of these cytokines might represent a possible mechanism used by IL-16/TPO combination to influence DC differentiation. We found indeed that the levels of both TGF- $\beta$ and IL-10 were higher in the milieu of developing IL-16/TPO-DCs than in the milieu of the other DCs. Next, we considered the possible mechanisms used by IL-16/TPO-DCs to induce tolerance of cocultured T-cells. The tolerogenic properties of IL-16/TPODCs could not be ascribed to an immature state because their surface expression of HLA and costimulatory molecules was not lower than expression on immunogenic DCs grown in the other cytokine combinations. However, "semimature DCs" have been described that induce T-cell tolerance despite their mature phenotype if they produce low levels of IL-12p70.24,27,28 Indeed, our results indicated that IL-16/TPO-DCs produced markedly lower levels of IL-12p70 than the other types of DCs. This finding, together with the observation that IL-16/TPO-DCs produce high levels of the immunosuppressive cytokines TGF- $\beta$ and IL-10, may suggest that an altered pattern of cytokine production may contribute to the tolerogenic properties of IL-16/TPO-DCs.

To further investigate other possible mechanisms used by IL-16/TPO-DCs to induce T-cell tolerance, we evaluated their surface expression of additional molecules involved in DC/T-cell interactions. DC-SIGN (CD209) is a recently identified DCspecific adhesion receptor belonging to the C-type lectin family, involved in the control of many functions of DCs including initiation and regulation of interactions between DCs and T cells..$^{29,30}$ Our results indicated that the expression of DC-SIGN was markedly decreased on IL-16/TPO-DCs and was directly correlated with the intensity of the induced T-cell proliferation. ILT-2, ILT-3, and ILT-4 belong to a family of inhibitory receptors that can be expressed on many cell types; it has been recently demonstrated that the expression of these molecules on DCs, induced by regulatory $\mathrm{T}$ cells, renders DCs tolerogenic. ${ }^{31,32} \mathrm{We}$ analyzed the expression of ILT molecules on our DCs and observed indeed that the expression of ILT-2, ILT-3, and ILT-4 was increased on IL-16/TPO-DCs and was inversely correlated with the induced proliferation of allogeneic $\mathrm{T}$ cells. Therefore, our results may suggest that low surface expression of DC-SIGN and high expression of ILT inhibitory molecules may represent additional mechanisms possibly involved in the tolerogenic properties of IL-16/TPO-DCs. 
Our results seem to indicate that the IL-16/TPO combination does condition the development of a distinct tolerogenic DC subtype that shares some features, but not others, with other defined DC subsets. In fact, similarly to Langerhans-type DCs, which are developed by culture of $\mathrm{CD} 34^{+}$cells in the presence of exogenous TGF- $\beta$ combined with GM-CSF, TNF- $\alpha$, Flt3L, and SCF, ${ }^{33,34}$ IL-16/TPO-DCs express the Langerhans cell-restricted molecule CD1a and lack DC-SIGN expression. But, unlike Langerhans-type DCs, which are immature DCs, they have a mature phenotype. Similarly to plasmacytoid DCs that can be developed by culture of $\mathrm{CD} 4^{+}$cells in the concomitant presence of Flt3L and $\mathrm{TPO},{ }^{35}$ IL-16/TPO-DCs express CD123 and produce IFN- $\alpha$. But, unlike these plasmacytoid DCs, they coexpress the myeloid marker CD11c. Notably, the possibility that these plasmacytoid features may contribute to the tolerogenic properties of IL-16/TPO-DCs appears unlikely because DCs coexpressing CD123 and CD11c and producing IFN- $\alpha$, obtained by culture of monocytes in GM-CSF plus IFN- $\alpha$, are endowed with excellent APC function, as we recently reported elsewhere. ${ }^{20}$

Last, we considered the effects of the cytokine combinations on the sorted subpopulations enriched in $\mathrm{CD} 34^{+} \mathrm{CD}^{+}$and $\mathrm{CD} 34^{+} \mathrm{CD} 4^{-}$cells. Our results clearly indicate that IL-16 is more effective on the $\mathrm{CD} 34^{+} \mathrm{CD} 4{ }^{+}$subpopulation. This finding is not surprising because secreted IL-16 is known to be the natural soluble ligand of CD4 molecule. ${ }^{36}$ Indeed, we observed that culture of $\mathrm{CD} 34^{+} \mathrm{CD}^{-}$cells in basal cocktail with or without IL-16 induced a progressive surface expression of CD4. Because CD4 expression was observed on a relevant percentage of cells after 3 to 4 days of culture, it may be argued that the proliferative effect of
IL-16 on $\mathrm{CD}^{+}$cells is mainly exerted during the first days of culture. Interestingly, the effects of IL-16 compared with basal cocktail were more marked on unfractionated cells, containing both $\mathrm{CD}^{+}{ }^{+}$and $\mathrm{CD} 4{ }^{-}$cells, than on sorted $\mathrm{CD} 34^{+} \mathrm{CD} 4^{+}$cells. We suggest that synergistic cooperation between different cell populations, with the possible involvement of other soluble factors, may be promoted by IL-16 in unfractionated cells and may be lost when the cells are sorted. On the other hand, IL-16/TPO combination was similarly effective on $\mathrm{CD} 34{ }^{+} \mathrm{CD} 4{ }^{+}$and $\mathrm{CD} 34^{+} \mathrm{CD} 4{ }^{-}$subpopulations in inducing the generation of tolerogenic DCs. Because IL-16 plus TPO exert their effects during the first days of culture, the possibility that some of the effects of IL-16 may be mediated not only by CD 4 receptor but also by other coactivators, as already reported elsewhere, ${ }^{37-39}$ may be considered. Further experiments will be required to clarify this point.

In conclusion, in this study we provide evidence that IL-16 and TPO may represent new tools for the in vitro generation of DCs from $\mathrm{CD} 34^{+}$progenitors. In different combinations with other cytokines they can improve the efficiency of generation of immunogenic DCs, or induce the generation of tolerogenic DCs that may aid the exploration of new therapeutic strategies to promote tolerance to autoantigens and prevent disease development.

\section{Acknowledgments}

We thank Dr M. Saresella and I. Marventano at IRCCS Fondazione Don Gnocchi, Milan, Italy, and I. Zaccaria at Ospedale S. Raffaele, Milan, Italy, for cell sorting.

\section{References}

1. Steinman RM. The dendritic cell system and its role in immunogenicity. Annu Rev Immunol. 1991; 9:271-296.

2. Cella M, Sallusto F, Lanzavecchia A. Origin, maturation and antigen presenting function of dendritic cells. Curr Opin Immunol. 1997;9:10-16.

3. Bancherau J, Steinman RM. Dendritic cells and the control of immunity. Nature. 1998;392:245252.

4. Lanzavecchia A. Mechanisms of antigen uptake for presentation. Curr Opin Immunol. 1996;8:348354.

5. Banchereau J, Briere F, Caux C, et al. Immunobiology of dendritic cells. Annu Rev Immunol. 2000; 18:767-811.

6. Ferlazzo G, Klein J, Paliard X, Wei WZ, Galy A Dendritic cells generated from $\mathrm{CD} 34^{+}$progenitor cells with flt3 ligand, c-kit ligand, GM-CSF, IL-4, and TNF-alpha are functional antigen-presenting cells resembling mature monocyte-derived dendritic cells. J Immunother. 2000;23:48-58.

7. Siena S, Di Nicola M, Bregni M, et al. Massive ex vivo generation of functional dendritic cells from mobilized CD34+ blood progenitors for anticancer therapy. Exp Hematol. 1995;23:1463-1471.

8. Rosenzwajg M, Gluckman JC. Problems raised by the in vitro generation of dendritic cells for use in immunotherapy. Exp Hematol. 1999;27:387378.

9. Caux C, Dezutter-Dambuyant C, Schmitt D, Banchereau J. GM-CSF and TNF-alpha cooperate in the generation of dendritic Langerhans cells. Nature. 1992;360:258-261.

10. Inaba K, Inaba M, Romani N, et al. Generation of large numbers of dendritic cells from mouse bone marrow cultures supplemented with granulocyte/ macrophage colony-stimulating factor. J Exp Med. 1992;176:1693-1702.

11. Cruikshank WW, Cente DM. Modulation of lym- phocyte migration by human lymphokines. II. Purification of a lymphotactic factor (LCF). J Immunol. 1982;128:2569-2571.

12. Cruikshank WW, Center DM, Nisar N, Natke B, Theodore AC, Kornfeld H. Molecular and functional analysis of a lymphocyte chemoattractant factor. Association of biologic function with CD4 expression. Proc Natl Acad Sci U S A. 1994;91: 5109-5113.

13. Cruikshank WW, Greenstein JL, Theodore AC, Center DM. Lymphocyte chemoattractant factor (LCF) induces CD4-dependent intracytoplasmic signalling in lymphocytes. J Immunol. 1991;146: 2928-2934.

14. Rand T, Cruikshank WW, Center DM, Weller PF. CD4-mediated stimulation of human eosinophils: lymphocyte chemoattractant factor other CD4 binding elicit eosinophil migration. J Exp Med. 1991;173:1521-1528.

15. Louache F, Debili N, Marandin A, Coulombel L, Vainchenker W. Expression of CD4 by human hematopoietic progenitors. Blood. 1994;84:3344 3355.

16. Berardi AC, Wang A, Levine JD, Lopez P, Scadden DT. Functional isolation and characterization of human hematopoietic stem cells. Science. 1995;267:104-108.

17. Ku H, Kaushansky K, Ogawa M. Thrombopoietin, the ligand for the $\mathrm{mpl}$ receptor, synergizes with Steel factor and other early acting cytokines in supporting proliferation of primitive hematopoietic progenitors of mice. Blood.1996;87:4544-4551.

18. Piacibello W, Sanavio F, Garetto L, et al. Extensive amplification and self-renewal of human primitive hematopoietic stem cells from cord blood. Blood. 1997:89:2644-2653.

19. Arrighi JF, Hauser C, Chapuis B, Zubler RH, Kindler V. Long-term culture of human CD34(+) progenitors with FLT3-ligand, thrombopoietin, and stem cell factor induces extensive amplification of a CD34(-)CD14(-) and a CD34(-)CD14(+) dendritic cell precursor. Blood. 1999;93:22442252.

20. Della Bella S, Nicola S, Riva A, Biasin M, Clerici $M$, Villa ML. Functional repertoire of dendritic cells generated in granulocyte macrophagecolony stimulating factor and interferon- $\alpha$. J Leukoc Biol. 2004;75:106-116.

21. Toba K, Winton EF, Bray R. Improved staining method for the simultaneous flow cytofluorometric analysis of DNA content, S-phase fraction, and surface phenotype using single laser instrumentation. Cytometry. 1992;13:60-67.

22. Nouri-Shirazi M, Guinet E. Direct and indirect cross-tolerance of alloreactive $T$ cells by dendritic cells retained in the immature stage. Transplantation. 2002;74:1035-1044.

23. Maika M, Janowska-Wieczorek A, Ratajczak J, et al. Numerous growth factors, cytokines, and chemokines are secreted by human $\mathrm{CD} 34^{+}$cells, myeloblasts, erythroblasts, and megakaryoblasts and regulate normal hematopoiesis in an autocrine/paracrine manner. Blood. 2001;97:30753085.

24. Hackstein $\mathrm{H}$, Thomson AW. Dendritic cells: emerging pharmacological targets of immunosuppressive drugs. Nat Rev Immunol. 2004;4:24-34.

25. Steinbrink K, Graulich E, Kubsch S, Knop J, Enk $\mathrm{AH}$. CD4(+) and CD8(+) anergic T cells induced by interleukin-10-treated human dendritic cells display antigen-specific suppressor activity. Blood. 2002;99:2468-2476.

26. Sato K, Yamashita N, Baba M, Matsuyama T. Modified myeloid dendritic cells act as regulatory dendritic cells to induce anergic and regulatory $T$ cells. Blood. 2003;101:3581-3589.

27. Lutz MB, Schuler G. Immature, semi-mature and fully mature dendritic cells: which signals induce tolerance or immunity? Trends Immunol. 2002 23:445-449. 
28. Menges M, Rossner S, Voigtlander C, et al. Repetitive injections of dendritic cells matured with tumor necrosis factor alpha induce antigen-specific protection of mice from autoimmunity. J Exp Med. 2002;195:15-21.

29. Van Kooyk Y, Geijtenbeek TBH. A novel adhesion pathway that regulates dendritic cell trafficking and T cell interactions. Immunol Rev. 2002;186: 47-56.

30. Figdor CG, van Kooyk Y, Adema GJ. C-type lectin receptors on dendritic cells and Langerhans cells. Nat Rev Immunol. 2002;2:77-84.

31. Chang CC, Ciubotariu R, Manavalan JS, et al. Tolerization of dendritic cells by $T(S)$ cells: the crucial role of inhibitory receptors ILT3 and ILT4. Nat Immunol. 2002;3:237-243.

32. Shiroishi M, Tsumoto K, Amano K, et al. Human inhibitory receptors Ig-like transcript 2 (ILT2) and ILT4 compete with CD8 for MHC class I binding and bind preferentially to HLA-G. Proc Natl Acad Sci U S A. 2003;100:8856-8861.

33. Strobl H, Bello-Fernandez C, Riedl E, et al. flt3 ligand in cooperation with transforming growth factor-beta1 potentiates in vitro development of Langerhans-type dendritic cells and allows single-cell dendritic cell cluster formation under serum-free conditions Blood. 1997;90:14251434

34. Soilleux EJ, Coleman N. Langerhans cells and the cells of Langerhans cell histiocytosis do not express DC-SIGN. Blood. 2001;93:1987-1988.

35. Chen W, Antonenko S, Sederstrom JM, et al. Thrombopoietin cooperates with FLT3-ligand in the generation of plasmacytoid dendritic cell pre- cursors from human hematopoietic progenitors. Blood. 2004;103:2547-2553.

36. Center DM, Kornfeld H, Cruikshank WW. Interleukin 16 and its function as a CD4 ligand. Immunol Today. 1996;17:476-481.

37. Zhang $\mathrm{XM}, \mathrm{Xu} \mathrm{YH}$. The associated regulators and signal pathway in rIL-16/CD4 mediated growth regulation in Jurkat cells. Cell Res. 2002;12:363 372.

38. Mathy NL, Bannert N, Norley SG, Kurth R. Cutting edge: CD4 is not required for the functional activity of IL-16. J Immunol. 2000;164:4429-4432.

39. Lynch EA, Heijens CA, Horst NF, Center DM, Cruikshank WW. Cutting edge: IL-16/CD4 preferentially induces Th1 cell migration: requirement of CCR5. J Immunol. 2003;171:4965-4968. 